\title{
FACTUALIDADE E CONTEXTO SEMÂNTICO-SINTÁTICO DO PRETÉRITO IMPERFEITO DO SUBJUNTIVO
}

\section{Angela Cristina Di Palma Back*}

(iD) https://orcid.org/0000-0002-4060-340X

Márluce Coann*

(iD) https://orcid.org/0000-0001-7809-8624

Como citar este artigo: BACK, A. C. D. P.; COAN, M. Factualidade e contexto semântico-sintático do pretérito imperfeito do subjuntivo. Todas as Letras - Revista de Lingua e Literatura, São Paulo, v. 23, n. 1, p. 1-13, jan./abr. 2021. DOI 10.5935/1980-6914/ eLETLL2113003

Submissão: dezembro de 2019. Aceite: julho de 2020.

Resumo: Nesta pesquisa, tratamos do pretérito imperfeito do subjuntivo com base em dois parâmetros: factualidade e contexto semântico-sintático. Apoiamo-nos em pressupostos funcionalistas e analisamos, qualitativa e quantitativamente, 350 dados orais. A análise da factualidade, por meio dos traços de referencialidade e particularização, revelou três identidades: 1. menos particularizado e mais referencial; 2. menos particularizado e menos referencial; e 3. mais particularizado e mais referencial. Da análise do contexto semântico-sintático, depreende-se o uso prioritário em adverbiais com escopo irrealis, destacando-se, também, os usos contrafactuais.

Palavras-chave: Imperfeito do subjuntivo. Factualidade. Contexto semântico-sintático. Irrealis. Contrafactuais. 


\section{A PROPOSTA: CONTEXTUALIZAÇÃo, DIRECIONAMENTO TEÓRICO E PROCEDIMENTOS}

E m geral, mencionar um tempo do subjuntivo implica caracterização de seu uso como irreal, incerto, duvidoso, hipotético... É o que se evidencia, por exemplo, em Cunha e Cintra (1979, p. 439), ao afirmarem que as formas do subjuntivo "[...] enunciam a ação do verbo como eventual, incerta ou irreal, em dependência estreita com a vontade, a imaginação ou o sentimento daquele que as emprega...". Reconhecem, ainda, que, além de passado, pode o pretérito imperfeito do subjuntivo (PIS) denotar os valores temporais de futuro, como em: "Alberto era inteligente e se não DEIXASSE engazupar, talvez aquilo até lhe FOSSE um bem...", e de presente, como em: "TIVESSES coração, terias tudo" (CUNHA; CINTRA, 1979, p. 462-463). Também Almeida (1989, p. 226) mostra que o imperfeito se presta à expressão de orações condicionais em que a hipótese é possivel ou irreal, ou, ainda, que seu uso, em certos casos, é elegantemente substituído pelo mais-que-perfeito do indicativo, como em "Estivera (=estivesse) eu presente, tal coisa não teria acontecido".

As noções de condição e incerteza como propriedades do PIS também se verificam em gramáticas mais antigas, como as de Barboza (1830) e de Pereira (1923). Este destaca o uso condicional do imperfeito: "Se elle VIESSE, eu sahia (sahiria)" (PEREIRA, 1923, p. 500). Aquele diz que o uso do subjuntivo não é meramente estrutural; ocorre para exprimir dúvida, medo, desejo ou vontade e, se assim não o fizer, não é subjuntivo. Além dessa observação, destaca a variação entre -sse (morfema modo-temporal de imperfeito do subjuntivo) e -ra (morfema modo-temporal prototípico do pretérito mais-que-perfeito do indicativo), para garantir-se simetria em todo o enunciado. Ilustra o caso com um exemplo retirado de um sermão do Pe. Antonio Vieira: "Se eu FORA hum dos beneméritos, em mim mesmo e no meu próprio merecimento achara tão grandes razões de me consolar, que sem outra mercê nem despacho, me dera por mui contente e satisfeito" (BARBOZA, 1830, p. 214 ).

Em oposição a uma caracterização do PIS como forma que expressa exclusivamente condição e incerteza, Bechara (2004, p. 214) argumenta que nem sempre o imperfeito se enquadra como algo inseguro, condicionado, distante da ação atual; é o que se observa, por exemplo, em expressões de polidez: "Se SOUBESSE, te dava a resposta”.

Fugindo à dicotomia certeza versus incerteza como caracterização, respectivamente, do indicativo versus subjuntivo, visamos a demonstrar que certeza é uma questão de grau. Parece-nos que, atualmente, todos os funcionalistas (no sentido filosófico do termo) estariam de acordo, mais propensos a análises escalares, não deixando de lado, porém, a discretude. De acordo com Givón (1995), os dois olhares são ingredientes necessários na representação e comunicação da experiência, não sendo, portanto, alternativas, mas visões complementares em sistemas complexos. A teoria dos protótipos (ROSCH, 1975) encaixa-se bem nessa perspectiva, como o próprio Givón (1995, p. 12) já alegava, pois lida com flexibilidade, fluidez, escalaridade, mas também categorialidade extrema nas margens.

Lidar, porém, com um tempo fluido como é o imperfeito do subjuntivo e com niveis de certeza poderia nos direcionar para a subjetividade extrema. Em terrenos assim, precisamos operacionalizar a análise por meio de parâmetros. É o 
que faremos neste artigo, ancorando-nos no funcionalismo givoniano (GIVÓN, 1990, 1993, 1995, 2001), especificamente em dois critérios: 1. factualidade (considerando os sintagmas nominais - SNs, se referenciais ou não referenciais) e 2. contexto semântico-sintático (considerando os tipos oracionais sob escopos modais). A relevância desta proposta está assentada na aplicação de critérios para análise da modalidade em dados do Português do Brasil, especialmente em dados do subjuntivo, modo menos explorado na literatura. Por razões operacionais, optamos por analisar separadamente cada critério, embora possam ser combinados entre si ou com outros.

Nossa proposta assemelha-se ao que traçamos para o PIS nos domínios da temporalidade e da aspectualidade (COAN; BACK, 2014), conforme Quadro 1 a seguir. Agora, operacionalizamos critérios no domínio da modalidade para que este domínio, como aqueles, possa ser mais bem caracterizado no que se refere ao emprego do imperfeito do subjuntivo em dados reais.

Quadro 1 - Identidades temporais e aspectuais do PIS

\begin{tabular}{|l|l|l|}
\hline \multicolumn{1}{|c|}{ Dominios } & \multicolumn{1}{|c|}{ Variáveis } & \multicolumn{1}{c|}{ Identidades } \\
\hline Temporalidade & Tempo funcional & $\begin{array}{l}1^{\text {a }} \text { Copretérito } \\
2^{\mathrm{a}} \text {. Futuro }\end{array}$ \\
\hline Aspectualidade & Aspecto da situação & $\begin{array}{l}1^{\mathrm{a}} \text {. Mais durativo (estado) } \\
2^{\mathrm{a}} \text {. Menos durativo (atividade) }\end{array}$ \\
\cline { 2 - 3 } & Visão da situação & $\begin{array}{l}1^{\mathrm{a}} \text {. Não atualização da imperfectividade } \\
2^{\mathrm{a}} \text {. Imperfectiva }\end{array}$ \\
\hline
\end{tabular}

Fonte: Adaptado de Coan e Back (2014).

Não bastasse arrolar traços para uma caracterização mais objetiva, o imperfeito do subjuntivo também será visto quantitativamente, dada a relevância do papel da frequência na modulação gramatical (FOX, 2007). Embora estejam em foco as acepções do PIS em termos de factualidade e de contexto semântico-sintático, investigamos a frequência com que se caracteriza cada uso nos dados, considerando o efeito da frequência na correlação da forma e da função, a partir da proposta de Fox. É uma analogia ao que Bybee (2002) chama de type frequency. Para a autora, a gramática é modulada pela frequência: token frequency (frequência de um item) e type frequency (frequência de uma categoria).

Utilizamos, para tanto, 350 dados do banco Entrevistas Sociolinguísticas, da Universidade do Extremo Sul Catarinense (Unesc). Embora não se pretenda estabelecer, nesta análise, correlações entre os usos do PIS e fatores sociais, os 60 informantes considerados para esta pesquisa são distribuídos ortogonalmente em células sociais, considerando-se sexo, idade e escolaridade, variáveis utilizadas para estratificação dos informantes que integram o banco de dados Entrevistas Sociolinguísticas.

Feita essa contextualização teórico-metodológica, passemos à discussão das duas características elencadas para análise do PIS: factualidade e contexto semântico-sintático. Visando garantir objetividade à proposta, examinamos, na seção 2, a factualidade por meio da referencialidade/particularização dos sintagmas nominais (SNs) e, na terceira seção, tratamos do contexto semântico-sintático por meio de tipos oracionais sob escopos modais. 


\section{A factualidade do PREtérito IMPerfeito do SUbJUntivo}

O primeiro dos critérios aplicados à análise dos dados de PIS é a factualidade, identificada via comportamento referencial dos SNs sob escopos modais. Para tal, levamos em consideração duas supermodalidades: [fato] - que engloba pressuposição e asserção realis; e [não fato] - que compreende a asserção irrealis ${ }^{1}$ e a asserção negada, conforme se observa no quadro que segue.

Guadro 2 - Modalidades epistêmicas

\begin{tabular}{|l|c|c|}
\hline \multicolumn{1}{|c|}{ Tradição lógica } & Equivalente comunicativo & Factualidade \\
\hline a. Verdade necessária & pressuposição & fato \\
\hline b. Verdade factual & asserção realis & fato \\
\hline c. Verdade possivel & asserção irrealis & não fato \\
\hline d. Não verdade & asserção negativa & não fato \\
\hline
\end{tabular}

Fonte: Givón (2001, p. 301).

Segundo Givón (2001), sob o escopo do não fato, os SNs podem ser interpretados como referenciais ou como não referenciais; já sob o escopo de fato, os SNs podem ser interpretados somente como referenciais. Adicionamos à análise mais um parâmetro que remete à situação ser ou não particularizada. Se houver uma situação particularizada, identificável, mesmo que não apareça um SN explícito no predicado, essa situação será interpretada como referencial; já a não existência de uma situação particularizada ou a habitualidade da situação indicarão menos referencialidade ou não referencialidade, ambas de interpretação menos factual.

Considerando-se que factualidade remete a contextos mais particularizados e mais referenciais, temos quatro combinações possiveis cujos resultados se encontram na Tabela 1, seguida de explicações, com base em ocorrências extraídas do nosso corpus.

Tabela 1 - Factualidade da situação e uso do PIS

\begin{tabular}{|c|c|}
\hline Fatores & Aplicação/total/\% \\
\hline [-particularização, +referencialidade] & $165 / 350 / 47,1$ \\
\hline [-particularização, -referencialidade] & $100 / 350 / 28,6$ \\
\hline [+particularização, +referencialidade] & $85 / 350 / 24,3$ \\
\hline [+particularização, -referencialidade] & 0 \\
\hline
\end{tabular}

Fonte: Elaborada pelas autoras.

1 A proposição realis é fortemente asserida como verdadeira, cuja contestação pelo ouvinte é apropriada, embora o falante disponha de evidência ou outras bases para defender sua crença. Já a proposição irrealis é fracamente asserida, ou como possível ou como provável ou como incerta (submodos epistêmicos), ou ainda como necessária, (in)desejada (submodos avaliativos/ deônticos), em que o falante não está pronto para reforçar a asserção com evidências ou outras bases fortes, e a contestação pelo ouvinte é prontamente recebida, esperada ou solicitada. 
Os percentuais totais expõem como fator preponderante o conjunto de traços [-particularização, +referencialidade], com 47,1\% de frequência, em oposição aos outros dois fatores, que mantêm um percentual semelhante (28,6\% e 24,3\%). Em princípio, quer nos parecer que o uso do PIS está acoplado a situações cuja referencialidade é resgatada de algum modo, mas não é particularizada (conforme evidencia o exemplo 01, a seguir), ou seja, as asserções tendem a não se referir semanticamente a um evento particular, ocorrido em um tempo especifico, mas acessam referentes disponíveis em alguma representação na memória.

(01) $E^{* 2} O$ que é o langor?

$F^{*}$ [...] langor é uma frente de duzentos metros debaixo da mina. [...] * Eles vão abrindo [...] uma galeria, mas lá era baixinho, [...] * O cara tinha que ficar ali ó, (risos I) abaixado, [...], um serviço perigoso e atrás iam os macacos, né? [...] * É quase tipo macaco de carro, um pouco diferente. * Calcava lá no teto, né?(est) *E aquela frente [...] explodia e ia ("detonando") tudo [...]. * Guando a gente, de vez em quando escutava, calcava o peso lá pra trás e acarcava e fazia aquela quebraçada [...] nós fazíamos uma taipa, que era obrigado a fazer uma taipa que ENCOSTASSE até no teto, uma taipa de pedra, $[. . .]^{*}$ Então encostava até assim no teto, só deixava um corredor pelo meio, né? [...] (SCCRI01, p. 4) ${ }^{3}$.

Em (01), a situação que contém o PIS é reiterada, isto é, apresentada como uma série de situações possíveis no passado, não se trata de situação única. Mesmo assim, a situação está mais próxima da factualidade por sua alta referencialidade no passado; embora não seja particularizada, não se trata de uma taipa específica. A ocorrência seguinte, (02), por outro lado, distancia-se da referencialidade, pois o PIS codifica uma situação não factual; trata-se de discurso opinativo com referentes genéricos: $T V$, todos os programas televisivos ou alguns programas televisivos.

(02) $E *$ O senhor acha certo a criança assistir qualquer horário, hoje, tudo?

$F^{*} E u$ acredito que não, não é certo assistir qualquer horário, agora, se ela está, ela vai assistir, daqui a pouco, tu vais fazer o quê? *Vais brigar, vais mandar dormir? *Não vai. *Sempre assiste, um dia ele não está, qualquer coisa, dá conta, acaba assistindo. *Então invés de ensinar pro mal, se ENSINASSE pro bem seria diferente, seria (SCCRI02, p. 23).

Segue-se, em (03), uma situação mais factual, já que visualizamos [+particularização, +referencialidade] em namorássemos, se a ocorrência for comparada a (02), em que o referente é genérico e a (01) cujo SN é referencial, porém não particularizado em virtude de ser indefinido.

(03) $F^{*}[. .]$.$* Nem perguntamos a idade um do outro. * Bom, eu com vinte e oito$ anos, eu me lembro eu tinha uma cara meia lisa ainda, né? (risos geral) * MaOs o cabelo não! (riso geral) * O cabelo não, o cabelo era grisalho.

$E^{*} E$ a diferença é de quanto tempo vocêOs dois?

$I^{*} \mathrm{DeOz}$ anos, não dá bem deOz anos.

[...] 
$F^{*}$ [ ( inint) ] a diferencinha é poca, é < Qua-> quase né_é nove anos e pouquinho.

I* Meu pai não queria que nós NAMORÁSSEMOS, que ele_

$E^{*}$ Ah maOs a diferença não, eu não acho que_

$I^{*} \mathrm{MaOs}$ só porque ele tinha jeito de ser mais velho, né? ${ }^{*}$ E o pai não tinha nem cabelo branco (est) *Então o pai dizia: “* Esse aí tem idade pra ser teu pai, e não sei o que, e brigava, brigava, ma0s foi no fim, a gente namorou, uns oito meses eu acho, namoramos, casamos..." (SCCRI01, p. 8).

Além de o sujeito, nesse caso (03), ser pronominal [+particularizado, +referencial], resgatamos, pelo contexto catafórico (tópico discursivo), a informação de que eles namoraram e casaram-se, atestando, portanto, a referencialidade da situação.

Ao observarmos a referencialidade dos usos do PIS por meio da análise dos SNs a que cada forma se vincula, chamou-nos a atenção, também, a vinculação entre factualidade e expressão do tempo, como podemos verificar na Tabela 2: quanto mais a situação se desloca no eixo passado, mais se associa à factualidade; inversamente, deslocando-se para o futuro, associa-se à não factualidade.

Tabela 2 - Distribuição dos dados de PIS por tempo e factualidade

\begin{tabular}{|l|c|c|c|c|}
\hline & $\begin{array}{c}\text { +particularização, } \\
\text { +referencialidade }\end{array}$ & $\begin{array}{c}\text {-particularização, } \\
\text { +referencialidade }\end{array}$ & $\begin{array}{c}\text {-particularização, } \\
\text {-referencialidade }\end{array}$ & Total \\
\hline Copretérito $^{4}$ & 44 & 89 & 05 & 138 \\
\hline Antepretérito & 04 & 07 & 02 & 13 \\
\hline Pós-pretérito & 27 & 27 & 01 & 55 \\
\hline Presente & 04 & 20 & 20 & 44 \\
\hline Antefuturo & 00 & 01 & 05 & 06 \\
\hline Futuro & 06 & 21 & 67 & 94 \\
\hline Total & 85 & 165 & 100 & 350 \\
\hline
\end{tabular}

Fonte: Elaborada pelas autoras.

Os números apresentados na Tabela 2 mostram polarização entre o eixo do pretérito (copretérito e pós-pretérito, principalmente) e do futuro (futuro). No eixo do pretérito, os fatores [+particularização, +referencialidade] e [-particularização, +referencialidade] estão fortemente correlacionados ao uso do PIS nos tempos funcionais de copretérito (respectivamente, 44 e 89 dados) e pós-pretérito ( 27 e 27 dados, respectivamente), ligando o PIS a situações factuais. Em outros termos, considerando-se os fatores relativos à factualidade, aproximadamente $90 \%$ dos dados com [+particularização, +referencialidade] distribuem-se no eixo temporal que reúne os três pretéritos (copretérito, pós-pretérito e antepretérito). Por outro lado, em se tratando do eixo do futuro, há [-particularização, -referencialidade],

4 As denominações aqui utilizadas para análise temporal provêm de Bello (1979 [1841], 1984 [1847]). Em especial, o copretérito equivale, neste artigo, ao pretérito imperfeito do subjuntivo, embora a terminologia se aplique ao imperfeito, tanto do indicativo quanto do subjuntivo. Conforme o autor, antepretérito equivale, em nossos dados, ao mais-que-perfeito (a passado do passado), bem como o pós-pretérito diz respeito ao futuro do pretérito. 
de modo que a direção da factualidade vai se configurando no sentido de comprovar a hipótese: [+tempo (em direção ao passado), +factualidade] Û [-tempo (em direção ao futuro, pois o futuro parece expressar/salientar mais modo do que tempo), -factualidade].

Disso decorre uma propriedade de configuração gramatical: o PIS evoca traços do campo irrealis (menos referencialidade; menos particularização e menos temporalidade). Esse olhar conduz-nos a uma reconfiguração analítica: uma forma pode ser analisada via traços, do que decorre a unidade prototípica de uma categoria e unidades que se afastam do protótipo por um ou mais traços. Olhando a Tabela 2 na vertical, fica evidente que o traço [-particularização] é o que mais caracteriza o PIS no corpus, se somados os 165 dados de [-particularização, +referencialidade] com os cem dados de [-particularização, -referencialidade]. No entanto, ainda percebemos mais usos referenciais (se somados os 85 + 165 dados que contêm essa propriedade). Quanto à temporalidade, a tabela vista na horizontal mostra mais dados no eixo do passado (se somados os dados de co, pós e antepretérito), embora haja um número considerável de dados associados ao presente e ao futuro.

Para além desses traços, investigar o contexto sintático do PIS pode auxiliar em sua configuração morfossintática e semântico-discursiva. Como aludido por alguns gramáticos e mencionado no início do artigo, a forma do subjuntivo remete a uma concepção marcadamente sintática, por isso julgamos relevante analisar, também, a estrutura oracional. Para tanto, consideramos, a seguir, com base em Givón (1993, 2001), a estrutura sintática, mas ampliamos a discussão incluindo a projeção semântica.

\section{O CONTEXTO SEMÂNTICO-SINTÁTICO DO PRETÉRITO IMPERFEITO DO SUBJUNTIVO}

A Tabela 3 aponta para uma variedade estrutural semântico-sintática que inclui: 1. substantivas (projetam [não]factivos, [não]implicativos, subjetivas [não]fato); 2. adverbiais (com escopo irrealis e contrafactuais); e 3. relativas com $\mathrm{SN}$ não referencial. Seguem-se à tabela explicações com ocorrências que ilustram cada um dos fatores.

Tabela 3 - Tipo oracional com escopo modal

\begin{tabular}{|l|c|}
\hline \multicolumn{1}{|c|}{ Fatores } & Aplicação/total $/ \%^{-1}$ \\
\hline Adverbial com escopo irrealis $^{5}$ & $201 / 350 / 57,5$ \\
\hline Contrafactual & $54 / 350 / 15,4$ \\
\hline Não factivo & $30 / 350 / 8,6$ \\
\hline Relativa com SN não referencial & $28 / 350 / 8$ \\
\hline
\end{tabular}

\footnotetext{
5 Embora Givón (2001) distribua as orações adverbiais em três grupos, a partir do escopo modal (escopo de pressuposição; escopo irrealis típico e escopo de negação), amalgamamos os casos de escopo irrealis e os de escopo pressuposicional, tendo em vista que ambos evocam eventualidade da situação descrita pelo PIS. Separamos, entretanto, os casos de escopo de negação, por não se tratar de eventualidade, mas de contrafactualidade.
} 
Tabela 3 - Tipo oracional com escopo modal (conclusão)

\begin{tabular}{|l|c|}
\hline \multicolumn{1}{|c|}{ Fatores } & Aplicação/total/\% \\
\hline Não implicativo & $17 / 350 / 4,8$ \\
\hline Subjetiva não fato & $08 / 350 / 2,3$ \\
\hline Subjetiva fato & $06 / 350 / 1,7$ \\
\hline Implicativo & $06 / 350 / 1,7$ \\
\hline
\end{tabular}

Fonte: Elaborada pelas autoras.

Em termos percentuais, o fator adverbiais com escopo irrealis, conforme ocorrência em (04), constitui contexto preferencial para uso do PIS. Vale ressaltar que essa interpretação é semântica e a estrutura sintática que a carrega não se limita ao contexto das condicionais, podendo se realizar como modal, temporal, locativa ou, ainda, concessiva, das quais 176 ocorrências são estruturas condicionais [se p então q], ou seja, dos 201 dados que projetam o fator em questão, $87,5 \%$ o fazem sob a forma de estrutura condicional. Em face do exposto e considerando os fatores listados na Tabela 3, a interpretação proposta para (04) é a de situação eventual, uma vez que a situação representada por escutasse não é factual, já que nem todo brasileiro escuta $A$ Voz do Brasil, nem é contrafactual, já que alguns brasileiros escutam $A$ Voz do Brasil, caracterizando-se, portanto, a situação como eventual, como hipótese ou de perspectiva.

(04) $F^{*}$ Tem gente que, que me chama de loØco porque eu escuto a voz do Brasil, se todo brasileiro ESCUTASSE a Voz do Brasil ele sabia tudo que era feito lá. *Porque a voz do Brasil é um programa informativo muito bom, tu sabeØ qual, qual é o projeto que foi aprovado, sabe qual é o projeto que está no diário oficial, sabe tudo e o pessoal, deu a hora do Brasil o pessoal já desliga o (Lush) já desliga o rádio. *Eu já soØ ao contrário, eu já ligo o rádio pØra escutar a voz do Brasil (SCCRI15, p. 15-16).

A tabela mostra, ainda, que as contrafactuais, conforme ocorrência (05), ocupam o segundo lugar na caracterização dos contextos de uso do PIS, com frequência de $15,4 \%$. Os contextos estruturais que identificamos em nossas análises ora são de comparativas, ora são de condicionais, com peso acentuado para essas últimas. Portanto, desses 15,4\% que equivalem a 54 ocorrências, $87 \%$ são condicionais. Prestes (2003) mostra alta incidência de orações condicionais nos contextos de contrafactualidade e de eventualidade (correlato ao escopo irrealis) ${ }^{6}$. Em função desse resultado, não é surpresa que esses fatores correlacionados aos tempos funcionais deem relevo ao copretérito, o que nos levou a entendê-lo como a função temporal não marcada e, portanto, esperada para o PIS.

(05) $F{ }^{*} E$ - só que um ídolo mesmo, no esporte, hoje seria o Guga, né? *Que+eu acho que+é um cara assim que [eu num] - eu se eu TIVESSE GANHO o que ele ganhoØ e todas as glórias que ele teve ultimamente, essa midia toda

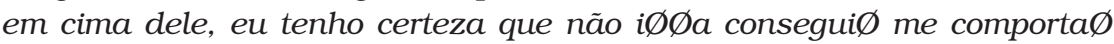

6 As condicionais eventuais/potenciais, por sua vez, têm o enunciado da apódose como certo, desde que eventualmente se satisfaça a condição enunciada; portanto, sua interpretação está fortemente vinculada ao valor hipotético, cujas representações temporais podem ser expressas no passado, presente e futuro (BELLO, 1979 [1841], 1984 [1847]; PRESTES, 2003; BACK, 2007). 
como ele se comporta assim, sabe? *SeØ aquele <mané>, tranqüilão, aquela coisa toda (SCCRI29, p. 13).

Diferentemente de (04), observa-se, em (05), a inversão de polaridade, conceptualização já destacada por Neves e Souza (1999), o que acaba por caracterizar a ocorrência como contrafactual:

a) prótase positiva: se eu tivesse ganhado $\mathrm{x}$ = pressuposto negativo: não ganhei $\mathrm{x}$.

b) apódose negativa: não ia conseguir me comportar = conteúdo asseverado positivo: o falante se comporta diferentemente.

Ambas as ocorrências, (04) e (05), retratam o uso do PIS sob o escopo do irrealis, no domínio semântico da certeza mais fraca. Esse uso é extremamente produtivo em nosso corpus, corroborando, em certa medida, os resultados obtidos por Givón $(1990,1993)$ para o Espanhol.

Quanto às chamadas orações subordinadas substantivas, que funcionam como complementos verbais oracionais, são aqui distribuídas considerando implicação (a verdade da oração principal implica/não implica a verdade do complemento) e factividade (a verdade da oração principal não necessariamente pressupõe a verdade do complemento). Essa análise correlaciona a oração subordinada que contém o PIS com a oração principal contendo verbos: 1 . de modalidade e auxiliares modais, 2. manipulativos e 3. de percepção-cognição-enunciação (GIVÓN, 1993, 2001). Parte-se, portanto, do pressuposto de que há forte relação isomórfica entre o significado do verbo na oração principal e a sintaxe de seus complementos. Evidentemente, esse isomorfismo não é tão patente quanto nas orações simples que o exibem de maneira mais acentuada, sobretudo quando comparadas às tratadas nesta seção. Por fim, há um número de predicados cujas proposições se dão por meio de sujeitos oracionais que vêm, também, a complementar a oração principal. A seguir, ilustraremos as ocorrências, enquadradas neste grande grupo, com exemplos mais representativos. Em (06), apresentamos uma ocorrência não factiva cuja asserção irrealis é depreendida com base na premissa de que a verdade da oração principal não necessariamente pressupõe a verdade do complemento. Trata-se de uma crença.

(06) [...] no tempo que eu viajava o dólar estava valendo menos que um real, no tempo que eu viajava [...] um dólar era oitenta e cinco centavos, aqui no Brasil a gente não acreditava que ele PUDESSE fazer isso aí, né? *Isqueiro a gente vendia aquela pencas de isqueiros [...] (SCRI03, p. 31).

A ocorrência (07) é um exemplar de relativa com escopo irrealis. Com apenas $8 \%$ de frequência, tais construções devem ser compreendidas como aquelas que podem codificar contraste entre SNs nucleares referenciais ou não referenciais. Os primeiros associam-se aos tempos do indicativo e os segundos aos tempos do subjuntivo (GIVÓN, 2001). Em se tratando das relativas, a amostra revelou, em princípio, que o PIS se associa às interpretações referenciais, a exemplo de $(07)$, em que se observa que o SN modificado pela oração relativa é definido e a entidade do discurso a que remete é a filha da informante, portanto, uma moça específica. Se nossa análise parasse aí, diríamos ser esse o contexto típico para o indicativo. No entanto, nota-se que a situação codificada não é particularizada, uma vez que a informante hipotetiza acerca de $n$ situações que poderiam ter 
acontecido em vários momentos, de modo habitual; e ainda se trata de uma negação: "não era aquela moça que...", portanto, a tal moça assim descrita, do ponto de vista referencial, até existe, mas carece do traço característico de asserções realis (evento específico em tempo específico). Logo, o contexto remete-nos à interpretação irrealis.

(07) F - Então por isso que eu amava a minha filha e o meu filho porque eles sempre me deram respeito e a minha filha era uma filha amorosa que nunca me deu problema de nada. Não era aquela moça que DISSESSE assim oh: "Eu vô lá" E eu dissesse não, era não (SCCRI019, p. 3).

Em (08), há uma exemplificação que evidencia um passado hipotético qualquer. A asserção também é irrealis, [não]implicativa, e deve ser compreendida dentro da perspectiva de que a verdade da oração principal não necessariamente implica a verdade do complemento.

(08) [...] eu, por exemplo, ia te tirar pra dançar. *Aí tu dizias: "Não danço contigo. Eu tenho par." "*Tudo bem, então vamos ver o teu par." [...] porque, às vezes, a gente, supor que tu FOSSES a minha namorada [...] eu ia dançar contigo, né? [...] (SCCRI005, p. 11-12).

Contrariamente à interpretação modal de (08), a ocorrência (09) remete ao realis, cuja verdade expressa pela oração principal implica a verdade de seu complemento. Trata-se de um implicativo.

(09) E-E você lembra do professor que você mais gostava?

$F$ - Do professor que eu mais gostava? Era minha professora da segunda série, que eu mais gostei. Só que eu não lembro o nome dela, maØs lembro dela, que ela sempre-= foi o único ano que eu não fiquei em nenhuma matéria. MaØs porque ela fazia a gente estuda Ø, maØs ela empolgava a gente estudaØ, ela se tu não se saia bem, ela ia lá, fazia ate tu te saiØ bem. Por isso que eu [não<fica->]- não fiquei, passei direto aquele ano. MaØs não porque ela me passou, foi porque ela fazia com que eu TIRASSE notas boas. Desde a primeØra série, eu sempre fiquei (SCCROI35, p. 3).

Finalmente, em relação à sintaxe da complementação, incluem-se, também, os verbos com sujeito oracional. A posição sintática pode ser aquela característica de sujeito, anteposto ao verbo; ou aquela reservada aos complementos objetos, pospostos ao verbo. As orações subjetivas, muitas vezes, confundem-se com as predicativas; a distinção entre elas decorre da perspectiva assumida e da ordem de disposição dos constituintes no período. Selecionamos duas ocorrências para tecer algumas considerações: (10) que diz respeito à interpretação de subjetiva sob o escopo do não fato e (11) que se refere à subjetiva sob o escopo do fato.

(10) $E *$ E hoje tu comes em plena segunda\#feira.

$F^{*} E$ qualquer hora [...] de segunda a segunda se come maionese e macarrão, maionese aquele tempo, a mamãe não sabia fazer maionese, nos não sabia fazer maionese, né? *Era arroz, macarrão, e feijão, refrigerante não se tomava, porque não podia comprar, ganhava pouco. *Não, hoje a vida é boa. *A mesma coisa, o Sérgio ontem quando tu ligaste, eu disse assim: "*Ah, eu vou marcar pra amanhã." *Tu marcaste pra hoje, o Sérgio assim: “*Ah, era bom que ela MARCASSE outra hora, que também eu queria falar" (SCCRI08, p. 6). 
(11) E* E o Guga, o que o senhor acha do Guga?

$F^{*}$ Eu não gosto de tênis, né? [...] *Eu não sei como é que a pessoa possa ficar uma hora, vendo [duas]-dois homens jogar tênis. *Eu gosto muito de futebol, maØs agora ele levou o nome de Santa Catarina, né? *Pena que não é de Criciúma, né? (risos E)*Melhor (seria) se FOSSE de Criciúma ainda, né?*MaØs ele é de Floripa, né? *MaØs ele levou o nome do Brasil, né? (SCCRI03, p. 52).

Em (10), o PIS é apresentado numa estrutura complexa em que a oração subjetiva se encontra posposta à principal, cujo predicado "era bom" expressa um viés modal irrealis deôntico. O uso do pretérito imperfeito do indicativo acrescenta um traço pragmático de polidez, atenuando a força deôntica, provavelmente por se tratar de um discurso reportado. Em (11), há fraca manipulação e a situação é contrafactual.

Com exceção dos poucos casos de implicativos e subjetivas factuais, os dados retratam o uso do PIS sob o escopo do irrealis, codificando estruturas sintáticas que denotam situações eventuais ou contrafactuais em estruturas condicionais; situações em que a verdade da oração principal não necessariamente pressupõe a verdade do complemento, ou seja, casos de subordinadas substantivas não implicativas, não factivas e subjetivas não fato; e, também, situações não referenciais em estruturas relativas.

\section{CONSIDERAÇÕES FINAIS}

A análise da factualidade, por meio dos traços referencialidade e particularização, e a análise oracional em perspectiva semântico-sintática mostraram ser possivel uma caracterização modal do PIS para além daquela puramente semântica (que o concebe como forma de codificação da incerteza) ou de outra eminentemente sintática (atrelada apenas à conexão oracional). Nosso olhar, ainda voltado a esses niveis, visou a articulá-los, fornecendo parâmetros para interpretar a modalidade irrealis do PIS; por consequência, demos relevo à categoria modalidade, embora sejam tempo e aspecto tão relevantes quanto a modalidade. Por conveniência expositiva, salientamos tempo e aspecto em Coan e Back (2014). Agora, o relevo foi da modalidade.

O que este artigo demonstra é a natureza escalar do uso do PIS em dados de fala. Da análise da factualidade da situação, nossos dados autorizam-nos a definir três identidades modais para o PIS nessa escala, da prototipia à periferia: 1. -particularizado e +referencial; 2. -particularizado e-referencial; 3. +particularizado e +referencial. Quanto aos tipos oracionais, é prototípica sua ocorrência em adverbiais com escopo irrealis, destacando-se, também, os usos contrafactuais, pois os demais casos ainda se encontram com percentuais abaixo de $10 \%$.

Reiteramos, portanto, o destaque deste artigo para a explicitação de critérios a serem aplicados em análise da modalidade, categoria discursiva, especificamente em dados do PIS. Aplicamos, por razões didáticas, os critérios em separado, mas evidenciamos a necessidade de tratá-los, em discussões futuras, combinados. 


\section{FACTUALITY AND SEMANTIC-SYNTACTIC CONTEXT FROM IMPERFECT PAST SUBJUNCTIVE}

Abstract: In this research, we analyze imperfect past subjunctive based on two parameters: factuality and semantic-syntactic context. We consider functionalist assumptions to analyze, qualitative and quantitatively, 350 oral data. The factuality analysis, by referentiality and particularization, has revealed three identities: 1. less particularized and more referential, 2. less particularized and less referential, and 3. more particularized and more referential. From the semantic-syntactic context analysis, the data indicate prior use in adverbial with irrealis scope, also standing out the counterfactual uses.

Keywords: Imperfect past subjunctive. Factuality. Semantic-syntactic context. Irrealis. Contratactuality.

\section{REFERÊNCIAS}

ALMEIDA, N. M. Gramática metódica da língua portuguesa. São Paulo: Saraiva, 1989.

BACK, A. C. D. P. A expressão verbal a serviço do efeito de sentido metafórico. Revista de Estudos Linguísticos, v. 15, n. 1, p. 39-56, 2007.

BARBOZA, J. S. Gramática philosophica da língua portuguesa. 2. ed. Lisboa: Lisboa, 1830.

BECHARA, E. Moderna gramática portuguesa. São Paulo: Editora Lucerna, 2004. BELLO, A. Análisis ideológica de los tiempos de la conjugación castellana. In: BELlO, A. Obra literaria. Caracas: Ayacucho, 1979 [1841]. p. 415-459.

BELLO, A. Gramática de la lengua castellana destinada al uso de los americanos. Madrid: Edaf, 1984 [1847].

BYBEE, J. Word frequency and context of use in the lexical diffusion of phonetically conditioned sound change. Language Variation and Change, v. 14, n. 3, p. 261-290, 2002.

COAN, M.; BACK, A. C. D. P. Identidades aspecto-temporais do pretérito imperfeito do subjuntivo. Cadernos de Estudos Linguísticos, Campinas, n. 2, p. 259-272, jul./dez. 2014.

CUNHA, C.; CINTRA, L. Nova gramática do português contemporâneo. 3. ed. Rio de Janeiro: Nova Fronteira, 1979.

FOX, B. A. Principles shaping grammatical practices: an exploration. Discourse Studies, v. 9, n. 3, p. 299-318, 2007.

GIVÓN, T. Syntax: a functional-typological introduction. Amsterdam: Philadelphia: John Benjamins Publishing Co., 1990. v. II.

GIVÓN, T. Verbal inflections: tense, aspect, modality and negation. In: GIVÓN, T. English grammar: a functional-based introduction. Amsterdam: Philadelphia: John Benjamins Publishing Co., 1993. v. 1.

GIVÓN, T. Functionalism and grammar. Amsterdam: Philadelphia: John Benjamins Publishing Co., 1995.

GIVÓN, T. Syntax. Amsterdam: Philadelphia: John Benjamins Publishing Co, 2001. v. 1. 
NEVES, M. H. de M.; SOUZA, E. M. As construções condicionais. In: NEVES, M. H. de M. (org.). Gramática do português falado. Campinas: Editora da Unicamp, 1999. v. VII.

PEREIRA, E. C. Gramática história. São Paulo: Editora Monteiro Lobato \& Cia., 1923.

PRESTES, G. J. Conteúdo temporal do imperfeito do subjuntivo em português. 2003. Dissertação (Mestrado em Linguística) - Pontifícia Universidade Católica do Rio Grande do Sul, Porto Alegre, 2003.

ROSCH, E. Human categorization. In: WARREN, N. (ed.). Advances in crosscultural psychology. London: Academic Press, 1975. 